\title{
Dirac's HdCdTe semimetals grown by MBE technology
}

\author{
Jakub Grendysa ${ }^{*}{ }^{1}$, Charles R.Becker ${ }^{1}$, Malgorzata Trzyna $^{1}$, Renata Wojnarowska-Nowak ${ }^{1}$, Ewa Bobko ${ }^{1,2}$ \\ and Eugen M. Sheregii ${ }^{1}$ \\ ${ }^{1}$ Centre for Microelectronics and Nanotechnology, University of Rzeszow, Pigonia 1, 35-959 Rzeszow, Poland \\ ${ }^{2}$ Institute of Physics, Polish Academy of Sciences, Lotników 32/46 Av., 02-668 Warszawa, Poland
}

\begin{abstract}
Peculiarities of the MBE growth technology for the Dirac's semimetal based on the $\mathrm{Hg}_{1-\mathrm{x}} \mathrm{Cd}_{\mathrm{x}} \mathrm{Te}$ alloys have been presented. Composition of layers was controlled by ToF-SIMS, FTIR measurements, and

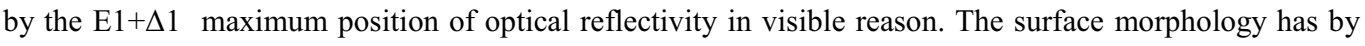
determined via atomic force and electron microscopy.
\end{abstract}

\section{Introduction}

Since 1958 the $\mathrm{HgCdTe}$ alloys are main material for infrared devices [1]. In last decade (from 2007 [2]]) a new property of this material, namely, inverted band structure caused by strong spin-orbital interaction, forms a new opportunity for this material - possibility to produce topological phase on surface. By this way, the Topological Insulators (TI) based on the $\mathrm{HgCdTe}$ became actual in $3 \mathrm{D}$ case [3].

In this short communication is presented peculiarity of the MBE technology designed to the strong TI producing based on semi-metallic $\mathrm{Hg}_{1-\mathrm{x}} \mathrm{Cd}_{\mathrm{x}} \mathrm{Te} \mathrm{Te}$ with $\mathrm{x} \leq 0.16$ what is semimetal yet but close to the $3 \mathrm{D}$ Dirac point .

\section{Experiment}

\subsection{MBE Grown}

The Dirac's semimetal $\mathrm{Hg}_{1-\mathrm{x}} \mathrm{Cd}_{\mathrm{x}} \mathrm{Te}$ epilayer samples has been grown in MBE system Riber Compact 21 with $\mathrm{CdTe}, \mathrm{Te}, \mathrm{ZnTe}, \mathrm{Hg}$, In standard cells and $\mathrm{CdI}_{2}$ cells with a special insert on the top to limit the value of the I flux. The $\mathrm{Hg}_{1-\mathrm{x}} \mathrm{Cd}_{\mathrm{x}} \mathrm{Te}$ :I we received using $\mathrm{Te}, \mathrm{CdTe}, \mathrm{Hg}$, and CdI2 source. Two type of substrates were used ) GaAs substrates (001) oriented were applied with the MBE grown CdTe buffer that produced $\sim 0.3 \%$ mismatch with the next thin MBE grown $\mathrm{Hg}_{1-\mathrm{x}} \mathrm{Cd}_{\mathrm{x}} \mathrm{Te}$ layer and CdZnTe substrates (112)B orientated were employed and the $\mathrm{Hg}_{1-\mathrm{x}} \mathrm{Cd}_{\mathrm{x}} \mathrm{Te}$ was grown directly on the CdZnTe(112)B substrate surface which have a lattice constant practically (with an uncertainty of $0.01 \%$ ).
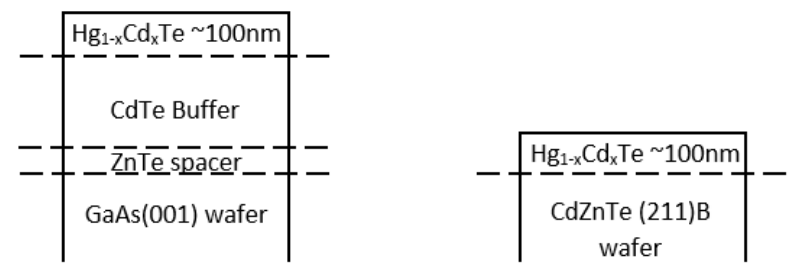

Fig. 1 The structure of the samples

Several conditions should be fulfilled during the growth process of the $\mathrm{Hg}_{1-\mathrm{x}} \mathrm{Cd}_{\mathrm{x}}$ Te layer with $0<\mathrm{x}<0.16$ of high quality - with surface close to ideal and low concentration of defects (hillocks).

At the very beginning we had to carefully prepare a substrate. Because they were used two types of substrate (See Fig. 1) were different ways to prepare them: i) for the GaAs substrate $(001)$ was enough degassing at $350^{\circ} \mathrm{C}$ and then deoxydation of the temperature of about $580^{\circ} \mathrm{C}$. ii) for the first $\mathrm{CdZnTe}$ substrate was rinsed in acetone, methanol, then a solution of $1 \%$ bromine in methanol [4] and dry nitrogen gas. Then, degassing at a temperature of $130^{\circ} \mathrm{C}$ (the temperature is lower as compared to those of GaAs substrate $\mathrm{CdZnTe}$ assembled on the carrier by indium), and oxygenate at $300^{\circ} \mathrm{C}$ (over $250^{\circ} \mathrm{C}$ above the point the flux on the substrate $\mathrm{Te}$ ).

The substrate temperature should be controlled with accuracy not worthy then $\pm 0.5^{\circ} \mathrm{C}$ because its strong influence on composition [5-7]. The substrate temperature determination need of specific calibration due to lack of physical contact for thermocouple with molybdenum substrate holder. Therefore, this thermocouple is calibrated by using the melting point of In, $\mathrm{Sn}$ and $\mathrm{PbSn}$ and $\mathrm{PbAg}$ on holder.

Next step is the determination and stabilization of the beam equivalent pressure (BEP) of sources is principally important at MBE growth for each compounds. In case 
of the $\mathrm{Hg}_{1-\mathrm{x}} \mathrm{Cd}_{\mathrm{x}} \mathrm{Te}$ layer growth additional factor is essential: stabilization of the Hg-flux is difficult and long - for two hours long [8]. The composition is determined by the $\mathrm{Cd} / \mathrm{Te}$ flux ratio whereas, the flux ratio $\mathrm{Hg} / \mathrm{Te}$ is important for quality of received layers $[5,8]$. Stabilization of these two ratio at the growth is crucible: deviation of BEP in the framework of $10^{-8}$ Torr able to change considerably the composition in the case of the $\mathrm{Cd} / \mathrm{Te}$ ratio as well as to increase the hillock density, electron concentration and decrease the electron mobility in the case of the $\mathrm{Hg} / \mathrm{Te}$ ratio [5]. To stabilize latter one we need two ours long operation of the sources temperatures. Simultaneously, the choose and stabilization of the flux parameters is complicated and it is necessary to prepare special computer program enables us to find corresponding flux values for Te and $\mathrm{Hg}$ when the CdTe fluxe is introduced: if the CdTe flux for the case of $x=0.15$ has value $2,9 \cdot 10^{-7}$ then the Te and $\mathrm{Hg}$ ones are correspondently chosen.

Last and very important step is the temperature regime of substrate after the end of process is also important in the case of the $\mathrm{Hg}_{1-\mathrm{x}} \mathrm{Cd}_{\mathrm{x}} \mathrm{Te}$ layer growth: it is necessary to leave the sample in atmosphere of mercury until the temperature of mountain decreases lower than $100^{\circ} \mathrm{C}$ in order to prevent the evaporation of $\mathrm{Hg}$ from surface.

As was mentioned above, accurate calibration of the BEP is cruel (particularly for $\mathrm{x}$ equal to about 0,15 ) and was performed by two steps: before insert the GaAs substrate into the chamber and at starting of the growth process. To stabilise the fluxes of Te, CdTe and $\mathrm{Hg}$ it is necessary to avoid of sudden changes of its values: such calibration should be made before any increase in order. Once known flux is what we want to get, (after initial calibration carried out immediately after loading of source materials and degassing main chamber MBE), it is possible to choose it prior to narrow down the temperature range for the interesting range.

Table 1 Parameters of strained and no strained Epitaxial Layers $\mathrm{Hg}_{1-\mathrm{x}} \mathrm{Cd}_{\mathrm{x}} \mathrm{Te}$

\begin{tabular}{ccccc}
\hline \hline & $\begin{array}{c}\text { Composition, } \\
\text { x, mol. }\end{array}$ & Substrate & Buffer & $\begin{array}{c}\text { Thickness, } \\
\mathrm{nm}\end{array}$ \\
\hline MCT & 0.157 & GaAs & ZnTe/ & 590 \\
32 & & $(001)$ & CdTe & \\
\hline MCT & 0.135 & $\begin{array}{c}\text { CdZnTe } \\
(112) B\end{array}$ & - & 100 \\
37 & & GaAs & ZnTe/ & 100 \\
\hline MCT & 0.135 & $(001)$ & CdTe & \\
41 & & GaAs & ZnTe/ & 100 \\
\hline MCT & 0.155 & $(001)$ & CdTe & \\
42 & & GaAs & ZnTe/ & 100 \\
\hline MCT & 0.135 & $(001)$ & CdTe & \\
44 & & &
\end{tabular}

It is important to start the growth of the fresh CdTe layer, preferably directly prior to actual growth. When the oxide layer is removed (the RHEED pattern is appeared) the PSCT temperature should be immediately decreases to $300^{\circ} \mathrm{C}$ and start with the $\mathrm{CdTe}$ buffer growth. The first was the layers of ZnTe (about $0.1 \mu \mathrm{m}$ ) as a small crystal lattice mismatch with respect to GaAs than the CdTe (3.5 $\mu$ m layer is applied [9] ).

In case of $\mathrm{CdZnTe}$ substrates the layer of $\mathrm{HgCdTe}$ we are grown directly at cleaned and deoxidation surface.

The next step is the opening of the valve spool of $\mathrm{Hg}$ and introduction of mercury into the main chamber by raising out of the external tank using elevators and heating $\mathrm{Hg}$ cell to a temperature at which we get the desired flux. It is a very long and important process, because the accuracy of the temperature settings strongly influence the fluxes and thus the $\mathrm{Hg} / \mathrm{Te}$ ratio what is important for "quality" of received layers $[8,10]$.

\subsection{Controlled of layers composition}

Composition of the resulting layers was controlled by Time-of-flight secondary ion mass spectrometry (ToFSIMS)[11] data were acquired using a ION-TOF GmbH TOF-SIMS V spectrometer. The analysis chamber was maintained at less than $5 \times 10^{-10} \mathrm{~Pa}$ under operational conditions. Sputtering was performed using the $2 \mathrm{keV}$ $(80 \mathrm{nA}) \mathrm{Cs}+$ ion beam, rastered over an area of $300 \times 300$ $\mu \mathrm{m}$. A pulsed $30 \mathrm{keV} \mathrm{Bi}+$ primary ion source at a current of $1.3 \mathrm{pA}$. (high current bunched mode), rastered over a scan area of $100 \times 100 \mu \mathrm{m}$ was used as the analysis beam. TOF-SIMS depth profiles were measured with the instrument working in the dual-beam mode.

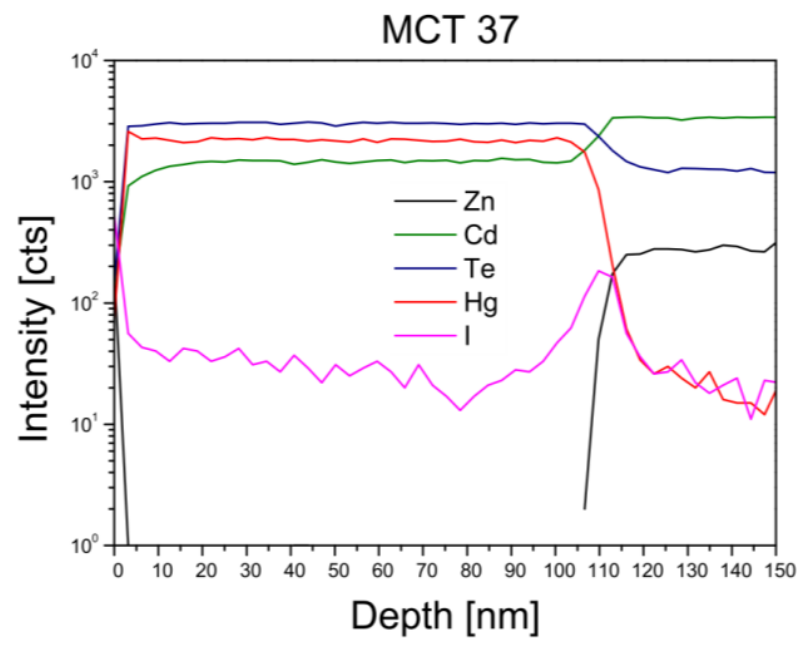

Fig. 2 Profile the downhole - Measurment ToF-SIMS of MCT37

The AFM measurements were performed using a AFM Inova Brucker in Taping Mode area $0,5-10 \mu \mathrm{m}$ at 512 line with $0,1-0,5 \mathrm{~Hz}$ 


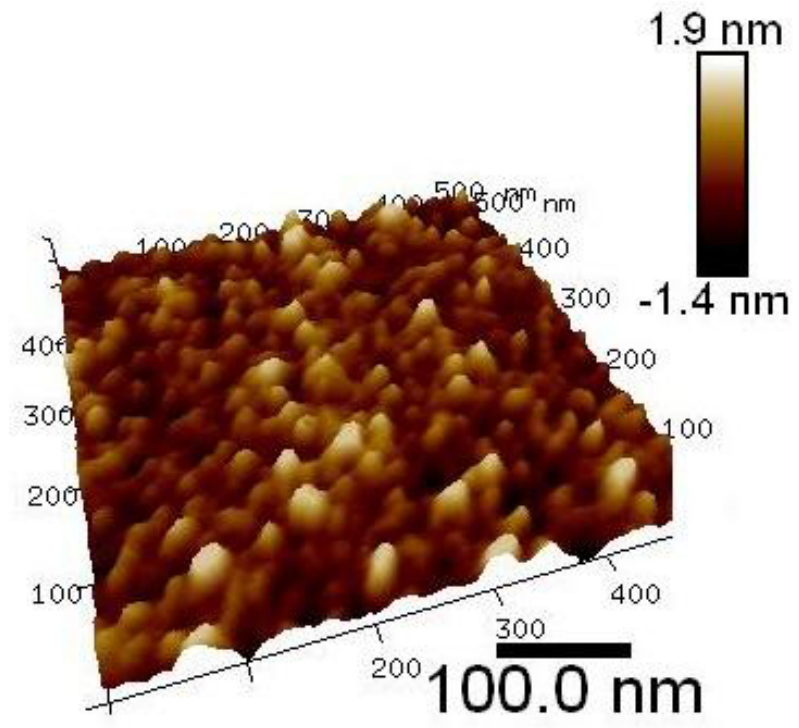

Fig. 3 AFM Hight resolution image of sample MCT37

The optical properties were studied by Fourier transform infrared (FTIR) spectroscopy method. The measurements were performed by Vertex 70v (Bruker) spectrometer, in the transmission mode. The FTIR spectra were obtained in the region of middle infrared $\left(400-7500 \mathrm{~cm}^{-1}\right)$, using 32 scans with spectral resolution of $2 \mathrm{~cm}^{-1}$.

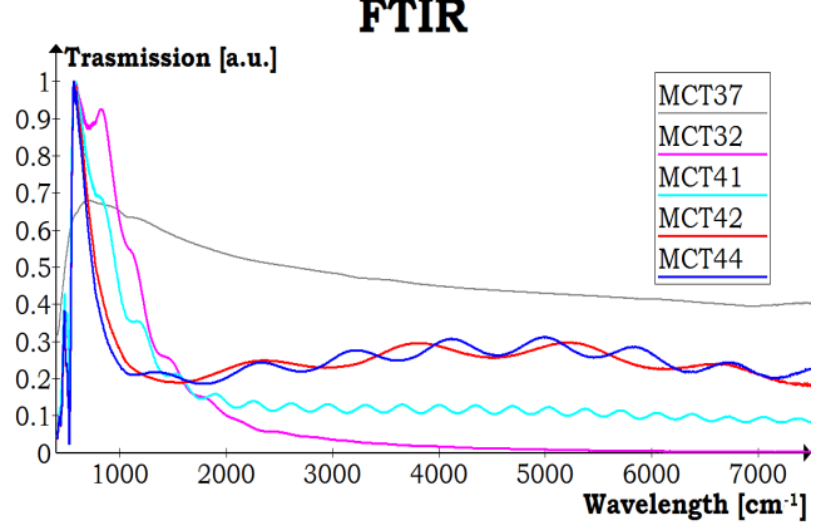

Fig. 4 The transmision of the sample in IR-FTIR measurements.

\section{Discussion and Conclusion}

In summary, more than forty layers have been grown by described above method. A quantized Hall conductance in the $3 \mathrm{D} \mathrm{Hg}_{1-\mathrm{x}} \mathrm{Cd}_{\mathrm{x}} \mathrm{Te}$ samples $(x<0.16)$ with thickness from 100 to $1280 \mathrm{~nm}$ and with different levels of $n$ type doping, using either iodine or indium as dopants, is observed over a wide temperature region from 0.4 to $50 \mathrm{~K}$. In case of sample grown on GaAs/CdTe substrates - MCT 37, 42, 44 - the clear Quantum Hall Effect was observed with quantized values of the Hall resistances in plateau equal to $R_{x y}=$ $h / v e^{2}$ ( $v$ is one integer) which was accompanied zero $R_{x x}$.
That means the strong TI was realized [6] enabled by applied effective MBE technology.

\section{Acknowledgments}

We acknowledge support from the authorities of the Podkarpackie Voivodship (Marshals Office of the Podkarpackie Voivodship of Poland), contract WNDRPPK.01.03.00-18-053/12.

\section{References}

1. R. Dornhaus and G. Nimtz, Narrow Gap Semiconductors 98, 159 (Springer-Verlag, Berlin, 1985)

2. M. König, S.Wiedmann, C. Brune, A. Roth, H. Buhmann, L. W. Molenkamp, Xiao-Lian Qi and S.C. Zhang, Science 318, 766-770 (2007)

3. G. Tomaka , J. Grendysa, P. Śliż, C. Becker, J. Polit, R. Wojnarowska, A. Stadler and E.M. Sheregii, Phys. Rev. B. 93, 205419-7 (2016)

4. J. Zhao, Y. Chang, G. Badano, S. Sivananthan, J. Markunas, S. Lewis, J. H. Dinan, P. S. Wijewarnasuriya, Y. Chen, G. Brill, and N. Dhar, J. Electron. Mater. 33, 881 (2004)

5. L. He, C. R. Becker, R. N. Bicknell-Tassius, S. Scholl, and G. Landwehr, J. Appl. Phys. 73, 3305 (1993)

6. J. Bajaj, J. M. Arias, M. Zandian, D. D. Edwall, J. G. Pasko, L. O. Bubulac, and L. J. Kozlowski, J. Electron. Mater. 25, 1394 (1996)

7. F. Goschenhofer, J. Gerschütz, A. Pfeuffer-Jeschke, R. Hellmig, C. R. Becker, and G. Landwehr, J. Electron. Mater. 27, 532 (1998)

8. J. Schmidt, K. Ortner, J. E. Jensen, and C. R. Becker, J. Appl. Phys. 91, 451 (2002)

9. L. He, S. Wang, J. Yang, M. Yu, Y. Wu, X. . Chen, W. Fang, Y. Qiao, Y. Gui, and J. Chu, J. Cryst. Growth 201, 524 (1999)

10. Y. Chang, C. R. Becker, C. H. Grein, J. Zhao, C. Fulk, T. Casselman, R. Kiran, X. J. Wang, E. Robinson, S. Y. An, and Others, J. Electron. Mater. 37, 1171 (2008)

11. L. Wang, L. H. Zhang, and J. Li, J. Electron. Mater. 28, 793 (1999) 